\title{
Correspondence
}

\section{Fluoxetine Supplement; 'Journal', September 1988, 153}

Dear Sirs

We have had a number of misgivings about the above Supplement, namely that it was promotional material, that Eli Lilly's sponsorship compromised the editorial standards of our Journal and that it creates a precedent for similar publications in the future.

Professor Freeman (Journal, January 1989, 154, 120-121) refuted these opinions by writing that the Fluoxetine Supplement "was peer-reviewed in accordance with the Journal's usual standards". However, we have recently noted that parts of this symposium have been reported elsewhere.

The same symposium on fluoxetine was also published as a supplement by another journal (Silverstone, 1989). Some of the reviews and research papers seemed to cover similar ground and the papers by Wernicke, based at Lilly Research Laboratories, and colleagues (Altamura et al, 1988; Wernicke et al, 1989) as far as we could tell, contained overlapping data. Altamura et al (1988) merely pooled data from two previously published clinical trials (Wernicke et al, 1988; Wernicke et al, 1987). Pooling data in this way can lead to misleading results (Simpson, 1951).

Both the New England Journal of Medicine (Angell \& Relman, 1989) and the British Medical Journal (Lock, 1989) have recently deplored the practice of redundant publication. This is particularly dangerous when reporting studies on a new drug because it can lead "unwary readers to give the conclusions more emphasis than they deserve. Patients or observations may even be counted twice" (Angell \& Relman, 1989). However, we would not wish to criticise the integrity or the scientific standing of Wernicke and collaborators as there are other appropriate publications for symposium proceedings and re-analysis of data: for instance, in separate monographs, books or symposium proceedings published independently of peer-reviewed journals.

Our concerns about the propriety of publishing such journal supplements have been amplified by this redundant publication. The International Committee of Medical Journal Editors (1988) has urged that "Multiple publication - that is, the publication more than once of the same study, irrespective of whether the wording is the same-is rarely justified". We therefore argue that the "usual standards of the
Journal" were compromised by accepting "the kind help of Eli Lilly International Corporation."

We respect that Professor Freeman's opinion on this matter differs from our own and that our letters on this subject to the Journal have been rejected. However, our impression is that a number of Members of the College are concerned about the policy of receiving money in exchange for publishing drug company supplements. We strongly disapprove of such use of the Journal and think it important that this potentially damaging policy should be debated as widely as possible amongst the membership.

ROB KERWIN

GLYN LEWIS

Institute of Psychiatry

Denmark Hill

London SE5 8AF

\section{References}

Altamura, A. C., Montgomery, S. A. \& Wernicke, J. F. (1988) The evidence for $20 \mathrm{mg}$ a day of fluoxetine as the optimal dose in the treatment of depression. British Journal of Psychiatry, 153, Supplement 3, 109-112.

Angell, M. \& Relman, A. S. (1989) Redundant publication. New England Journal of Medicine, 320, 1212-1214.

Freeman, H. (Ed) (1988) Progress in antidepressant therapy. British Journal of Psychiatry, 153, Supplement 3.

INTERNATIONAL COMmTTEE OF MEDICAL JOURNAL EDITORS (1988) Uniform requirements for manuscripts submitted to biomedical journals. British Medical Journal, 296, 401-405.

Lock, S. (1989) Publication: duplicate, salami, meat extender - all redundant. British Medical Journal, 298, 1203-1204.

SIL VERSTONE, T. (ed) (1989) Clinical studies of fluoxetine in depression. International Journal of Psychopharmacology. 4, Supplement 1.

SimPSON, E. H. (1951) The interpretation of interaction in contingency tables. Journal of the Royal Statistical Society, 13, 238-241.

WERNICKE, J. F., BOSOMWORTH, J. C. \& ASHBROOK, E. (1989) Fluoxetine at $20 \mathrm{mg}$ per day: the recommended and therapeutic dose in the treatment of depression. International Journal of Psychopharmacology, 4, Supplement 1,63-67.

, DUNLOP, S. R., DORNSEIF, B. E. \& BOSOMWORTH, J. C (1988) Low dose fluoxetine therapy for depression. Psychopharmacology Bulletin, 24, 183-188.

- - - \& ZerBe, R. L. (1987) Fixed dose fluoxetine therapy for depression. Psychopharmacology Bulletin, 23, 164-168. 